\title{
High functioning autism and prosody of sentence types in Greek: A case study
}

\author{
Maria Tripolitou ${ }^{1}$, Anthi Chaida ${ }^{2,3}$ \\ ${ }^{1}$ Queen Margaret University of Edinburgh, UK \\ ${ }^{2}$ Department of Speech \& Language Therapy, AKMI Metropolitan College, Greece \\ ${ }^{3}$ Laboratory of Phonetics \& Comptational Linguistics, University of Athens, Greece \\ https://doi.org/10.36505/ExLing-2011/04/0035/000204
}

\begin{abstract}
The study focuses on the prosodic characteristics of sentence types in Greek, based on data by an adult with high functioning autism (HFA). It investigates the effects of the disorder on tonal and temporal features of 2 basic sentence types. A production experiment was carried out, based on SVO sentences produced as statements and polar questions, with no other difference than their prosodic realisation. The HFA findings were compared to relevant findings for normal speech and showed: (a) very similar tonal patterns, (b) more expanded tonal, and (c) longer utterances.
\end{abstract}

Key words: prosody, intonation, sentence types, high functioning autism, Greek.

\section{Introduction}

This study reports on the prosodic characteristics of sentence types in Greek, based on a case study of an adult with high functioning autism (HFA). It aims to investigate the effects of HFA on tonal and temporal features of 2 basic sentence types: statement and polar question. The results were compared to relevant findings for normal speech.

\section{High functioning autism and prosody}

Communicative dysfunction is a core symptoms of autistic syndromes in individuals who speak, although there is no significant delay in language development of people with HFA. Expressive language is often stereotyped. Vocal characteristics can be very different in these individuals. Differences reported include monotonic or machine-like intonation, deficits in the use of pitch and control of volume, deficiencies in vocal quality, and use of aberrant stress patterns. Productions may sound rather flat, due to monotone, robotic phrasing, artificial sounding and inflection patterns (Happé, 1996). When these differences are present, they tend to be persistent and show little change over time (Shriberg et al., 2001). HFA speakers may produce utterances without a terminal pitch contour, and may have either very narrow or very wide tonal ranges, also lacking correlation between frequency and intensity (Baltaxe et al., 1984). However, HFA it has been reported that tonal boundaries may be adequately used to locate ends of utterances (Fine et al., 1991). Wide pitch variations have been also noted. HFA speakers have been reported to produce longer utterances with high variability

ExLing 2011: Proceedings of 4th Tutorial and Research Workshop on Experimental Linguistics, 25-27 May, Paris, France 
(Baltaxe et al., 1984). Prosodic deficits in HFA, however, have not been universally reported, in general, while -to our knowledge- there is no relevant research concerning the Greek.

\section{Prosodic patterns of sentence types in Greek}

In Greek, in the absence of lexical information, the distinction between sentence types is assumed to depend on the prosodic structure. Sentence types are associated with local and global tonal structures. Questions are mostly associated with higher tonal register, less tonal declination and a final tonal rise (e.g. Botinis, 1998). Studies in Greek prosody have revealed several tonal features that distinguish each sentence type (e.g. Baltazani, 2007; Botinis, 1998; Chaida, 2007, 2010; see Fig. 1).

$\begin{array}{|llc|}\text { Sentence Type } & \text { Tonal structure } & \begin{array}{c}\text { Boundary } \\ \text { Low } \\ \text { STATEMENT }\end{array} \\ \text { POLAR QUESTION } & & \begin{array}{c}\text { Rise-Fall } \\ \hline\end{array}\end{array}$

Figure 1. Stylized tonal structures for statement and polar question in Greek (adapted from Chaida, 2007, 2010).

\section{Methodology}

Hereby, we present a production experiment based on a case study of a 43year-old female adult with HFA, native speaker of Greek, with the ability to read. The speaker produced three SVO sentences, as statements and polar questions, based only on prosodic variations, without any other lexical, morphological or syntactical information given. The phonetic material consisted of a corpus of 60 sentences in total (10 repetitions X 3 randomised repetitions X 2 sentence types). Three F0 measurements were taken per syllable, while the length and the pitch range of each utterance were also noted down. The recorded speech samples were analyzed and assessed in contrast to the results of a control group of 5 female normal speakers (Chaida, 2010).

\section{Results}

HFA findings are presented in comparison to normal speakers' findings in Table 1 and Figures 2-4.

As shown in Table 1, the pitch range is higher in statement than in question, both in HFA and normal speech. It should be noted that the pitch range in HFA is significantly higher than the pitch range in normal speech $(\mathrm{t}(\mathrm{df} 2)=7.28, \mathrm{p}=0.01)$. 
High functioning autism and prosody of sentence types in Greek 145

Table 1. Mean pitch range (in $\mathrm{Hz}$ ) of statements and questions in HFA and normal speech (female speakers).

\begin{tabular}{|l|c|c|c|c|}
\hline Speakers & Sentence Type & Min. & Max. & Pitch Range \\
\hline \multirow{2}{*}{ HFA } & STATEMENT & 106 & 338 & 232 \\
\cline { 2 - 5 } & QUESTION & 107 & 316 & 209 \\
\hline \multirow{2}{*}{ Normal } & STATEMENT & 173 & 254 & 81 \\
\cline { 2 - 5 } & QUESTION & 162 & 269 & 107 \\
\hline
\end{tabular}

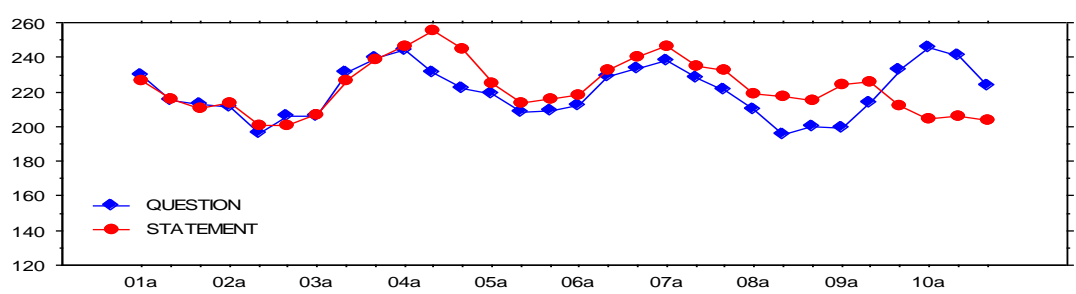

Figure 2. Mean tonal patterns $(\mathrm{Hz})$ of statement and question by an HFA female speaker.

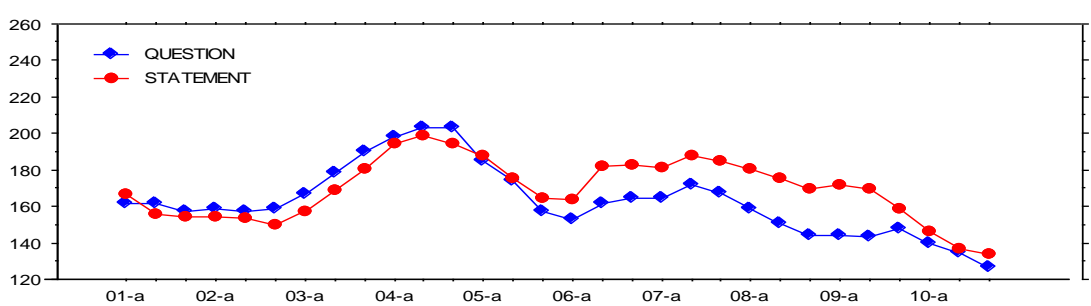

Figure 3. Mean tonal patterns $(\mathrm{Hz})$ of statement and question by 5 normal female speakers.

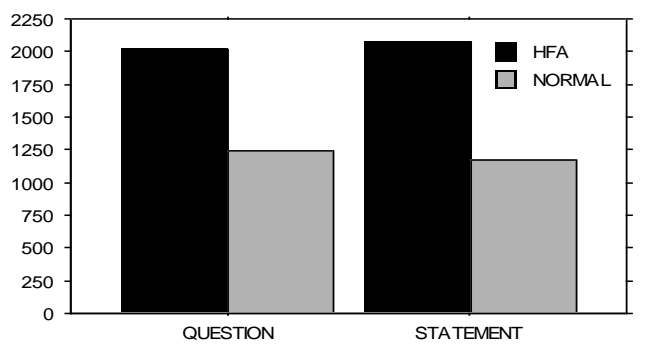

Figure 4. Mean duration (in ms) of statements and questions in HFA normal speech (female speakers).

As presented in Fig. 2-3, regarding intonation, the tonal pattern for statements shows very few differences: the utterance tonal offset in HFA is higher than the one in normal productions. Regarding questions in normal speech, the peak of the rise-fall of the tonal boundary is aligned with the 
final stressed syllable of the utterance, i.e. the pre-final syllable of the utterance. In HFA, the peak of the tonal boundary rise-fall in questions is aligned with the final syllable of the utterance, while it is a lot higher than in normal speech, leading to a higher utterance tonal offset. The difference between HFA and normal tonal patterns is statistically significant for questions $(\mathrm{t}(\mathrm{df} 928)=2.03, \mathrm{p}=0.01)$, but not for statements $(\mathrm{t}(\mathrm{df} 928)=1.55$, $\mathrm{p}=0.11$ ).

Sentence type differences with regards to duration, are of no significance both for HFA and normal productions, as shown in Fig. 4. However, the duration difference between HFA and normal speech is highly significant, both for questions $(771,80 \mathrm{~ms} ; \mathrm{p}<0.0001$, at 0.05 level) and for statements (900,95 ms; $\mathrm{p}<0.0001$, at 0.05 level).

\section{Conclusions}

The results give a clear picture that HFA sentence type production. HFA findings showed very similar tonal characteristics to normal speech, concerning the intonation of statements and polar questions in Greek. However, the tonal range of the HFA speaker is significantly more limited than that reported for normal female speakers. With regards to temporal characteristics, HFA productions were found to be significantly longer than the normal ones. The prosodic deficits frequently attributed to people with autistic syndromes reside primarily in the pragmatic and affective aspects of prosody, with grammatical aspects relatively spared (Shriberg et al., 2001). In general, HFA intonation findings of the present study revealed that there is a clear distinction between sentence types, indicating that prosody may not be considered as a major communicational constraint for people with HFA.

\section{References}

Baltaxe C.A.M., Simmons J.Q., Zee E. 1984. Intonation patterns in normal, autistic and aphasic children. In Cohen A. \& Van de Broecke M. (eds), Proc. of the 10th International Congress of Phonetic Sciences, Dordrecht: Foris.

Botinis, A. 1998. Intonation in Greek. In Hirst, D. and Di Cristo, A. (eds), Intonation Systems: A Survey of Twenty Languages. CUP, 288-310.

Chaida A. 2007. Tonal Structures of Complex Sentences in Greek. In Proc. of the 8th International Conference on Greek Linguistics, Ioannina, Greece.

Chaida A. 2010. [in Greek] Production and perception of sentence type intonation in Greek. PhD Thesis, University of Athens, Greece.

Fine J., Bartolucci G., Ginsberg G., Szatmari P. 1991. The use of intonation to communicate in pervasive developmental disorders. Journal of Child Psychology and Psychiatry, 32, 777-782.

Happé F. 1996. Autism. London: UCL Press.

Shriberg L.D., Paul R., McSweeney J., Klin A., Cohen D.J., Volkmar F.R. 2001. Speech and Prosody characteristics of adolescents and adults with high functioning autism and Asperger syndrome. and Hearing Research, 44, 1097-1115. 